both Houses on this question, the Council of the British Association may be able to do a work of great national importance by pointing out clearly and definitely what must be done, and by the publication of an annual report on the progress made preventing the subject again being allowed to drop.

\section{STELLAR OBJECTS SEEN DURING THE ECLIPSE OF 1869}

$\mathrm{T}$ will be remembered by the reader who has interested 1 himself in the published reports of observations of recent total eclipses of the sun, that during the totality on August 7, 1869, at a point in Iowa, called St. Paul's Junction, several observers attached to a party organised by Mr. W. S. Gilman, of New York, remarked below the sun what they termed "a little brilliant," and that one of the number using a small telescope, reported baving seen just before the sun disappeared and as he came out again a minute crescent, in a similar direction from the moon. Commodore Sands, then Superintendent of the Naval Observatory, Washington, expressed his regret that these objects should not have been seen by Mr. Gilman himself, who had experience of the use of the telescope and was using a larger instrument than the others who had optical aid-but"his "plan of operations" did not permit of it. The facts are thus stated :-A few moments after the corona formed, a small but exceedingly bright point, like a star, was noted independently by four of the party, two of whom it is mentioned were observing without telescopes; it appeared near the limits of the corona, below the moon's disc, and with one exception the observers located it a little to the right of an "anvil-shaped" prominence, or "at about $230^{\circ}$ from the north point, reckoning by the east," and it is added that each of the observers felt quite positive that what he saw was truly a star. With respect to the small crescent Mr. Gilman reports that about half a minute preceding totality another member of the party, Mr. Vincent, came to him exclaiming that he saw a miniature-crescent-shaped star under the moon, and asking him to verify the observation, but, interested in his own work, he did not at the moment do so; on $\mathrm{Mr}$. Vincent returning more urgent than ever, Mr. Gilman says he did look in a hurried manner but saw nothing in the few seconds he gave to the search; he afterwards states, however, that he does not think he looked so far away from the moon as the crescent was located in a drawing made immediately after the eclipse by Mr. Vincent; in this drawing it was placed "at one and a half times the moon's diameter from its limb, and to the left of a perpendicular down to the horizon." $\mathrm{Mr}$. Gilman adds he could not connect this crescent with the small star of the other observers, indeed Mr. Vincent estimated the object seen by him at three times as far removed from the moon's limb as the small star, which would assign for the latter a distance of about half a degree, corresponding very well to the expression used by the four observers who noted it, that it was near the limits of the corona. Dr. B. A. Gould, now Director of the Observatory at Cordoba, who observed this eclipse at a different station, gave some attention to a search for any object near the sun which might be in intra-Mercurial planet, and he states he saw the star $\pi$ Cancri, but did not meet with any other stellar body. This star being at the time in a similar direction from the moon's centre, to "the little brilliant" of the Iowa observers, there has been a pretty general opinion that it was the object remarked by them, and, in conversation with Dr. Gould several years since, I found him tolerably well satisfied that he had thus sufficiently explained their observations. But the discovery, or rather discoveries, of Prof. Watson, lend a new interest to them, and a more strict examination of the circumstances may not be out of place here. The position of St. Paul's Junction is stated to be in latitude $42^{\circ} 47^{\prime} 30^{\prime \prime} \mathrm{N}$., and longitude $19^{\circ} 5^{\prime} 45^{\prime \prime} \mathrm{W}$. of Washington. The totality was observed to commence at $5 \mathrm{~h} .48 \mathrm{~m} .46 \mathrm{~s}$, ending at $5 \mathrm{~h}$. $5 \mathrm{Im} .34 \mathrm{~s}$. M.T. at Washington, so that the middle occurred at $10 \mathrm{~h} .58 \mathrm{~m} .22 \mathrm{~s}$. M.T. at Greenwich, which agrees exactly with a calculation made with the Nautical Almanac elements. We will assume 10 . 59m. G.M.T. as the time to which the observations of the brilliant point apply. Correcting the moon's place for the effect of parallax, we find her apparent position at this time to be in right ascension, 9h. IIm. 26.7s., and north declination $16^{\circ} 13^{\prime} 58^{\prime \prime}$; her augmented semi-diameter was $16^{\prime} 37^{\prime \prime}$. We must assume that both star-like object and crescent were on an angle of $230^{\circ}$, the latter one. and-a-half times the moon's diameter from her limb, and the former at one-third of this distance, whence, referring to the moon's centre, we have, for the crescent, $\Delta a=$ $-3 \mathrm{~m} .32 \mathrm{~s}, \Delta \delta=-42^{\prime} \cdot 7$, and for the bright little star, $\Delta a=-\mathrm{Im} .46 \mathrm{~s} ., \Delta \delta=-2 \mathrm{I}^{\prime \prime} 4$; and thus,

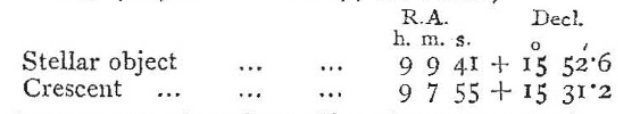

The former was therefore $28^{\prime}$ and the latter $56^{\prime}$ south of the ecliptic.

Now with regard to the star, the presence of which has been supposed to explain the observation of the four observers who noted "the little brilliant," there has been some slight confusion. In a note inserted in the last "Annual Report" of the Royal Astronomical Society it is stated that the object seen "has been satisfactorily identified as the star $\pi^{1}$ Cancri," which is assuredly a mistake. $\pi^{\mathfrak{i}}$, according to Argelander, is only a seventh magnitude, which is hardly to be glimpsed with the most acute sight in the darkest winter sky. For $\pi^{1}$ no doubt we must read $\pi^{2}$, or 82 Cancri. But this star, also, is of a degree of brightness wholly insufficient to allow of it being possible to discern it at all so near the sun's place without some optical aid in the still illuminated sky-ground, much less to be caught up as a brilliant point of light, with the naked eye ; the "Durchmusterung" estimate is $5.8 \mathrm{~m}$., which is confirmed by the careful estimations of the second Radcliffe Catalogue, where we find it rated $5.9 \mathrm{~m}$., or, in round magnitudes, a sixth. It should be mentioned that the apparent place of 82 Cancri was in right ascension 9h. 7m. 59.5s., declination $15^{\circ} 28^{\prime} 56^{\prime \prime}$, agreeing nearly with that we have found for the minute crescent, but $33^{\prime}$ from the small star. It appears probable, in view of Prof. Watson's discovery, that Dr. Gould may have mistaken an intra-Mercurial planet for $\pi^{2}$ Cancri, and if the statements of the four observers at St. Paul's Junction (one of them, by the way, a lady) are accepted, it can hardly be doubted that they also were 
attracted by an unknown object, since in that part of the sky there is no star which could be visible as they describe it. It is significant that Regulus, upwards of $12^{\circ}$ from the sun's place, was only noticed as "a glimpse-star" at St. Paul's Junction.

J. R. HIND

\section{LAKE DWELLINGS}

The Lake Dwellings of Switzerland and other Parts of Europe. By Dr. Ferdinand Keller. Second edition, greatly enlarged. Translated and Arranged by John Edward Lee, F.S.A., F.G.S. Two vols, (London: Longmans. 1878.)

$T^{T}$ is ten years since the first edition of Dr. Keller's valuable work was published, and since that time vast additions have been made to a knowledge of the subject of which it treats. Mr. Lee, besides incorporating in the present edition the whole of $\mathrm{Dr}$. Keller's Seventh Report, gives short accounts of every lake settlement that has been investigated; and an idea of the progress that has been made in this department may be learned from the fact that in the first edition the number of objects drawn and described numbered about 1,500 , whereas in the present edition they number between two and three thousand.

The second volume, a thick one, is entirely occupied with illustrations of the portions of lake dwellings that have been found, of the situations in which the remains exist, and of the multitude of objects that have been collected in situ. As a frontispiece to the first volume is given an illustration of a restored lake dwelling, which nestling near the shore of a Swiss lake, in a picturesque situation, backed by trees and overtopped by lofty mountains, makes a very pleasant picture. Over the fence which surrounds the edge of the platform we see the sloping roofs of the huts built thereon, and out in the lake two boats fishing by means of nets. There is some difficulty, it seems, as to the question of windows, Mr. Lee contending that the huts must have contained these, as the inhabitants would of ten have to work at their flint implements by the side of the fire. But we scarcely think windows necessary on this account; we have frequently seen the peasants in Scotland, in the long winter evenings, carry on knitting and other even more delicate work by the light of the fire or at most with the addition of a lighted spill of resinous pine. On the whole, however, Mr. Lee's restoration is likely to be a pretty close approximation to reality, to judge from the mass of data collected in Dr. Keller's work.

After an introduction describing the various forms of lake dwellings, the methods used in collecting the relics, on the original discovery of the dwellings, and a few sensible remarks on the ages of stone, bronze, and iron, each of the lakes in which dwellings have been found is treated of separately, the nature of the remains described, and an attempt made to realise the actual nature of the original work. Sections, for there are no chapters, are devoted to the discussion of special objects found and of special points and circumstances connected with the structures, the life and habits of the builders, and the environment generally. One of the most interesting sections is that on the Geographical Distribution of Lake Dwellings, from which we see that they have been found in many other places besides Switzerland--in Germany, Austria, France, Ireland, Scotland, and Wales. Mr. Lee rightly includes under the general head of Lake $D$ wellings the Crannoges of Ireland, Scotland, and Wales; for although those of Ireland at least were in several important respects different from the structures found on the Continent, still they have several strong points of resemblance. The reason for the choice of site was no doubt pretty much the same-security from sudden attack. Remains of lake-dwellings have even been found in the heart of London, in the peaty marsh where Finsbury now stands, and where, "in Romano-British times, some outcast natives lived." Gen. Lane Fox describes these remains in the Anthropological Review for April, 1867. Dr. Keller has always been adverse to the idea of lake-dwellings having been circular; but just when the English work was completed, Mr. Lee tells us that the author sent him word of remains of an undoubted circular dwelling having been found at Fang, in the Lake of Morat. Very interesting are the sections by Prof. Oswald Heer on the plants of the lake-dwellings, and by Prof. Riitimeyer on the animals.

From the mass of data which has been collected, Dr. Keller gives a very clear account of the general form of these lake settlements, and of the different varieties under which they may be classed. As to the substructure, first of all of pile dwellings, which are by far the most numerous in the lakes of Switzerland and Upper Italy. Piles of various kinds of wood sometimes split, but in general mere stems with the bark on, sharpened sometimes by fire, sometimes by stone hatchets or celts, and in later times by tools of bronze and probably of iron, were driven into the shallows of the lakes, provicled they were not rocky, at various distances from the shores. Sometimes the piles were close together, sometimes wide apart. On the level tops of the piles were laid the beams, which were sometimes fastened by wooden pins and sometimes let into mortises cut in the heads of the piles. Sometimes the vertical piles were strengthened by cross timbers below the platform beams. Generally the platform itself consisted of one or two parallel layers, and was of very rude structure, though sometimes the stems were split and joined together with some approach to accuracy. The distance from shore seems to have varied considerably; but it is curious that when a lake dwelling had been inhabited both in the stone and bronze ages, that part evidently used in the bronze age is frequently further from the shore and deeper in the lake than that which belongs to the age of stone. Otherwise, nearly the same mode of construction prevailed in the pile-dwellings during the ages of stone, bronze, and iron. In some cases, at least, there is evidence that the dwellings were comnected with the shore by a narrow platform or bridge, formed also of piles. In certain cases, also, it is seen that artificial elevations were made on the bed of the lake by piles of stones brought in boats; one of these boats, still loaded with stones, is to be seen at Peters Island, on the Lake of Bienne. The stones must have been put down after the piles had been driven more or less deeply into the mud.

Certain forms, known as frame-pile dwellings, have been found in the Lake of Zürich. In this form the piles, instead of having been driven into the mud of the 